\title{
Editorial
}

\section{COVID-19. Narrativas y consideraciones sociales, culturales y políticas. Los otros virales}

Citar como: Castro, R. (2020). COVID-19. Narrativas y consideraciones sociales, culturales y políticas. Los otros virales. Desde el Sur, 12(1), pp. 5-10.

Estamos aún en medio de la pandemia y seguimos teniendo muchas preguntas acerca del origen y la propagación del nuevo coronavirus, así como de sus letales consecuencias por todo el mundo. En los centros de investigación más importantes se han ensayado algunas respuestas sobre su origen y performance, pero en ningún caso se han obtenido respuestas definitivas. Esta situación de incertidumbre propicia activos caldos de cultivo para numerosas y disímiles interpretaciones, y muchas de ellas son encendidas por las llamadas teorías de la conspiración. Si hay, pues, en este largo y lamentable proceso de contagio histórico para la humanidad, una gran víctima general, ella es la información sustentada, es decir, elaborada con rigor y responsabilidad. Sobre todo en los llamados medios sociales de internet.

Existen decenas de virales desinformativos propagándose veloz y activamente por las distintas plataformas de socialización. En nuestros chats en WhatsApp, en nuestros muros de Facebook o en nuestras búsquedas simples en Google se ciernen versiones diversas e inverosímiles sobre el origen del mal. La más reciente: la que le atribuye a China un plan estratégico para usar la nueva tecnología de telefonía móvil $5 \mathrm{G}$, sobre la que dicen las versiones que facilitan la expansión de la enfermedad, siembran el caos y se dirigen a apoderarse así del control del planeta. Otra explicación le atribuye al propietario fundador de Microsoft, Bill Gates, el financiamiento de su creación, con la finalidad de enriquecerse aún más desarrollando la vacuna mediante su fundación Bill \& Melinda Gates. Aún más vacua es la 
versión que dice que es un arma biológica desarrollada en la NASA y enviada a China para debilitar su creciente influencia.

No es un asunto de países con sistemas educativos insuficientes. La cadena alemana Deutsche Welle (2020) reveló que, en 2019, un estudio de opinión entre los ciudadanos germanos encuentra que el $46 \%$ de la población cree que existen organizaciones secretas que influyen en la toma de decisiones políticas. Y no es solo en el valle del Rin. Otro estudio reciente en el Reino Unido, llevado a cabo por investigadores del King's College de Londres, encontró que el $56 \%$ de ingleses no cree que haya evidencia sólida que demuestre la existencia de la COVID-19. La mayoría de ellos se informa a través de Facebook y otras redes de socialización digital, plataformas sobre las que se sostiene este despliegue de desinformación (Freeman et al., 2020).

Con mucha frecuencia las explicaciones corren de la mano de figuras mediáticas que las impulsan. El cantautor español Miguel Bosé, apreciado intérprete en el mundo hispano, fue sujeto de escarnio por sostener incendiarios reclamos contra Bill Gates en una versión aún más enrevesada que las antes reseñadas. Bosé explica que el plan de Gates consiste en inocular nanobots a la población, endodérmicos, mientras se aplican las vacunas, mediante los cuales se manipularía a las personas utilizando precisamente la irradiación $5 \mathrm{G}$ con mandatos de comportamiento que nos robotizarían (Mendiola, 2020). Bosé fue trending topic y empujó hashtags como \#exposebillgates.

Por banal que pueda parecer citar a Bosé, o a productos mediáticos que proliferan en las redes, que son citados y discutidos sin descanso, como el filme de YouTube Plandemic - el que en sus 26 extenuantes minutos hace un alegato anticientífico preñado de información fake-, 
lo que las comunidades científicas afrontan es un cuestionamiento serio a su misma razón de ser. En el camino se está construyendo un argumento que indica que no hay investigación científica independiente. Que a cada hallazgo de investigación corresponde un interés detrás. Que a cada nuevo desarrollo se le conoce luego un entramado de capitales dispuestos a lucrar con él. Consecuentemente, las orientaciones que hay en la opinión pública sobre la misma actividad científica, que se constatan, nos obligan a ocuparnos de los escepticismos que comprenden intrínsecamente, pues son extensos, enraizados en sesgos atávicos, y empujan a que sean las ciencias sociales, humanas y de la comunicación las que tengan ahora mucho que investigar y luego recomendar con énfasis en políticas públicas. Sobre todo en un contexto de emergencia sanitaria como el que vivimos.

Hay pioneros. La jefatura editorial de la revista Scien$c e$, por cierto, se encargó de desactivar, afirmación tras afirmación, los serios arrestos de desinformación y mensajes anticientíficos que propulsó el mencionado filme de YouTube mediante un intenso trabajo colaborativo de factchecking. La voz dominante en Plandemic es la viróloga Judy Mikovits, una frecuente asistente a cónclaves antivacunación. Es medular el trabajo de las ciencias sociales, humanas y de la comunicación en su combate, pues de por medio está la lucha contra estas campañas, que son letales y propician el incremento sustancial de los índices de mortalidad, y que regresan con ello a estadios de épocas oscuras. Science se encargó así de desmontar la narrativa relacionada con la inutilidad de las indicaciones sanitarias, como el uso de mascarillas y hasta de los hechos simplemente inexistentes, como que Mikovits había sido arrestada por sus supuestos hallazgos contrarios al uso de retrovirales contra el HIV (Ensenrink y Cohen, 2020). 
Antes de la pandemia, las bromas sobre los terraplanistas (grupos de presión ciudadanos que creen que el mundo tal cual lo conocemos es una simulación de los poderes mundiales que nos estamos creyendo) eran celebradas. Hoy preocupan. Los negacionistas científicos están ganando terreno, y lo que anteriormente pudo haberse creído que eran leyendas folclóricas de la era digital, hoy, lamentablemente, se tornan amenazas para la gobernabilidad de los países. Lo dicho es complejo porque alienta a la desobediencia civil y a no aceptar o respetar las normas sanitarias dictadas por los regímenes, debido a que, según sostienen, ejercen una suerte de biopoder destinado a dominar toda voluntad independiente.

Al cierre de la edición de este número especial de Desde el Sur - un medio académico de divulgación de investigaciones científicas-, tenemos ingratas noticias sobre la acción de un grupo religioso, evangelista cristiano, en la Amazonía peruana, que inyectó un medicamento veterinario a miles de personas para "tratarlos», supuestamente, contra la COVID-19. Al menos 5000 peruanos en la región de Loreto, muchos de ellos nativos indígenas, ingirieron esta vacuna antiparasitaria con el argumento de que era «una salvación» ante la enfermedad. La ausencia del sistema de salud formal, de organismos públicos y de la academia misma, física e informativamente, en la región, es patente, lo cual deja el camino libre para que actúen agentes que fácilmente transmiten información errada y letal (Fowks, 2020).

Investigaciones recientes, como la de Orduña-Malea et al. (2020), reportan que el número de videos sobre la COVID-19 durante la pandemia aumentó considerablemente, de la mano de la lógica mayor demanda por la preocupación ante la enfermedad. El mismo informe alerta sobre el grave problema que constituye la información sin 
base o desinformativa para la eficiencia de las campañas de medios, Estados y organismos (Orduña-Malea et al., 2020). Ante este panorama, centros de investigación líderes en el mundo, como el King's College, llaman la atención de las principales plataformas de social media para que tengan mayor y más eficiente regulación sobre estas falsedades perniciosas. Sobre la base de una investigación de Freeman et al., publicada en Psychological Medicine, antes mencionada, la BBC afirma al respecto que la gente en el Reino Unido que se informa masivamente en los medios sociales tiene más disposición de quebrar las normas de la cuarentena. Por lo que concluye: «las plataformas de social media no autorreguladas, como YouTube o Facebook, presentan riesgos para la salud [...] porque ellas expanden teorías conspirativas sobre el coronavirus» (Easton, 2020).

Con lo dicho, se torna ya una certeza afirmar que las ciencias de la salud no son las únicas que tienen materia pendiente por investigar y aplicar en su trabajo. Más que nunca, las ciencias sociales, humanas y de la comunicación, tienen el imperativo de investigar el comportamiento de las personas, sus procesos de intercambios de información, y la formación de corrientes de opinión y sentidos comunes, que guían sus actos y sentimientos, con el fin de reducir la incidencia negativa de la información falsa, y de sus consecuencias nefastas. Hacer ciencias sociales, humanas y de la comunicación, ahora mismo, es una materia que puede hacer la diferencia entre la vida y la muerte.

\author{
Raúl Castro Pérez \\ Universidad Científica del Sur \\ ccastroperez@cientifica.edu.pe
}




\section{REFERENCIAS BIBLIOGRÁFICAS}

Deutsche Welle (2020). Especial coronavirus. Conspiraciones y estigmas. Recuperado de https://youtu.be/EFzZddpAPEY

Easton, M. (2020). Coronavirus: Social media «spreading virus conspirancy theory». BBC. Recuperado de https://www.bbc.com/news/uk-53085640

Ensenrink, M. y Cohen, J. (2020). Fact-checking Judy Mikovits, the controversial virologist attacking Anthony Fauci in a viral conspiracy video. Science Mag. Recuperado de https://www.sciencemag.org/news/2020/05/ fact-checking-judy-mikovits-controversial-virologist-attacking-anthonyfauci-viral

Fowks, J. (2020). Un grupo evangélico peruano inyecta un medicamento veterinario a miles de personas para la covid-19. El País. Recuperado de https://elpais.com/sociedad/2020-06-19/un-grupo-evangelico-peruanoinyecta-un-medicamento-veterinario-a-miles-de-personas.html

Freeman, D., Waite, F., Rosebrock, L., Petit, A., Causier, C., East, A., Jenner, L., Teale, A.-L., Carr, L., Mulhall, S., Bold, E. y Lambe, S. (2020). Coronavirus conspiracy beliefs, mistrust, and compliance with government guidelines in England. Pyschological Medicine, 1-13, DOI: https://doi.org/10.1017/ S0033291720001890

Mendiola, J. (2020). Bill Gates estalla (y Miguel Bosé se desboca). Yahoo! Finanzas. Recuperado de https://es-us.finanzas.yahoo.com/noticias/billgates-estalla-miguel-bos\%C3\%A9-001950855.html

Orduña-Malea, E., Font-Julian, C. y Ontalba Ruipérez, J. A. (2020). Covid-19: Análisis métrico de videos y canales de comunicación en YouTube. Profesional de la Información, 29(3). 